\title{
The Search for a Culture of Bribery in Cameroon
}

\author{
Lincoln J. Fry ${ }^{1 *}$ \\ ${ }^{1}$ Academic Member, Sociology Research Unit, Athens Institute for Education and Research (ATINER), \\ Athens Greece, Florida, USA \\ *Lincoln J. Fry, E-mail: Lincolnfry@ bellsouth.net
}

\begin{abstract}
Introduction: This paper addresses systematic corruption in Cameroon. Based on the literature review and a previous study, the research question was "does a culture of bribery exist in Cameroon, and what are its predictors? Method and materials: Data for this study was collected by the Afrobarometer project from 1,200 Cameroonian respondents Based on self-reported data, the research attempted to determine the volume of bribes paid by respondents to receive public services. Results: Overall, the findings revealed the existence of a culture of bribery in Cameroon; forty-five percent of the respondents reported paying bribes within the last year and 30 percent reported paying two or more bribes in that same time period. Logistical regression analysis revealed that 7 variables were significant predictors of payment of bribes. Being the victim of a property crime was the strongest predictor, which, in turn, drew attention to the role of the police in Cameroon's bribery culture.
\end{abstract}

\section{Keywords}

Cameroon, corruption, culture of bribery, infrastructure, property crimes, violent crimes

\section{Introduction}

Corruption can occur on different scales. There is corruption that occurs as small favors between a small number of people (petty corruption). There is corruption that affects the government on a large scale (grand corruption), and corruption that is so prevalent that it is part of the everyday structure of society (systemic corruption). Petty corruption occurs at a smaller scale and within established social frameworks and governing norms. Examples include the exchange of small improper gifts or use of personal connections to obtain favors. This form of corruption is particularly common in developing countries and where public servants are significantly underpaid. This paper will focus specifically on Cameroon, and this study will show that petty corruption is so widespread that it meets the criteria to be labeled systematic corruption.

\section{The Literature Review}

Corruption in Africa: as Chitakunye et al. (2015) indicated, corruption has been described as an intractable global problem from which no nation or region can claim exemption. Hope (2014) describes corruption in Africa as a culture and corruption is seen as part of the social fabric of African countries. 
According to Blundo and de Sardan (2006), daily life in Africa is governed by the "petty" corruption of public officials in services such as health, transport, or the judicial system. There is a growing body of literature about the extent and impact of corruption on other societal domains in developing countries, like infrastructure (Kenney, 2006), provision of health care (Siverson \& Johnson, 2014), foreign aid (Asongu, 2012), and the public's confidence in public institutions (Clausen, Kraay, \& Nyiri, 2011). Anoruo and Braha (2005) reported that corruption directly retards economic growth by lowering productivity, and indirectly by restricting investment. Justensen and Bjornskov (2012) described corruption as a major source of slow development in Africa, and indicated that corruption and bribery are directly related to poverty, because poor people rely on services provided by the government and therefore are more likely to be victims of corrupt behavior by street level government bureaucrats. This means poor people are those most likely to pay more than their fair share of bribes.

While some see corruption as the sand in the wheels of growth, like Wei (2000), others see corruption as having a positive effect on countries, acting as the grease that moves the economic development process along (Meon \& Seekat, 2005). Some have argued that corruption may serve a useful function when it causes commerce to work more effectively. Some scholars take the position that bribery in general may be ethical in cases where it may be a helping hand, but unethical when it is paid to a grabbing hand where nothing is offered in return for the payment (Colombatto, 2003; Egger \& Winner, 2005; Houston, 2007). Wong and Beckman (1992) did develop a point system to determine whether the helping or grabbing hand predominates.

\subsection{Corruption, the Police and Infrastructure in Cameroon}

According to Ndedi, Alain and MUA (2015) and Kingsley (2014), corruption has been a long standing problem in Cameroon. In 2014, Transparency International ranked Cameroon at 136 of the 175 countries included in the CPI (Corruption Perception Index) in 2014 and the country was ranked 164 of 181 in the World Banks Doing Business Index. Dominguez-Torres and Foster (2011) noted that 79 percent of Cameroonians admitted paying bribes. Besides business, the police have received special attention in the literature devoted to corruption in the country. According to NORAD (2015), the Cameroonian Police are perceived to be the most corrupt public institution in Cameroon. Police profit from roadblocks, and individuals in Cameroon reportedly pay police bribes to secure their freedom or to pass through roadblocks. People reportedly bribe the police to arrest or harass individuals involved in personal disputes.

Infrastructure in Cameroon has been a special concern in the literature. Dominguez-Torres and Foster's paper (2011) asked and answered the question as to why infrastructure matters. They argue that if Cameroon can improve its infrastructure, economic growth could be increased greatly. However, they point out that in the face of rapid population growth, especially urban sprawl, this growth has taken place without links to infrastructure. About 70 percent of Cameroon's urban population and all of the poorest urban residents have no access to public utilities. 
Further rationale for this paper was provided by earlier studies generated by the Afrobarometer Project, the data source used in this research. These papers include Peiffer and Rose (2014), Justensen and Bjornskov (2012), Richmond and Alpin (2013), and Bleck and Michelitch (2015).

Infrastructure, or lack thereof, has been a major interest in these papers. So has some recently published papers on this topic. One important paper was produced by Leo, Ramachanddran and Morello (2015). They noted that infrastructure improvement is a top level economic, political, and social issue in nearly every African country. They also noted there is an extensive academic and policy literature about the impact of infrastructure deficits on economic and social indicators. Yet, very few studies have examined citizen demands for infrastructure. Leo, Ramachandran and Moeello produced infrastructure data from 33 countries included in Afrobarometer, Round 5. The purpose was to move toward a basic understanding of service availability as perceived by citizens in each country. They found a predictable pattern of infrastructure services across income levels; lower-income countries have fewer services. The survey data also allowed the authors to observe the sequencing of infrastructure services. While survey respondents were most concerned with jobs and income-related issues, they were also concerned with the availability of infrastructure, specifically transportation and sanitation. These are priorities which transcend demographic factors, including gender and location (urban/rural).

Another recent Afrobarometer paper by Bleck and Michelitch (2015) dealt with a single country, Mali, and thus serves as a precursor to the purposes of this paper. That paper provides the perspectives of rural Malians living on the border of state-and rebel-controlled territory during a major crisis in the country, a coupe and a secessionist insurgency. Using a mixed methods approach, Bleck and Michelitch found it was not the political situation that rural villagers found, as "the crisis". Rather it was the unmet needs for public services and infrastructure. The state breakdown mattered less because the state had not been present in the first place. Rather than the state, villagers were largely reliant on local traditional authorities. The authors concluded that the salience of villagers' concerns about public services and infrastructure, as well as general insecurity related to basic needs, were consistent with the rest of Africa. In fact their findings echoed cross-national Afrobarometer data on public service provision across rural and urban areas. Their conclusion was that for all sub-Saharan African countries, the urban-rural gap is large, with absolute levels of rural provision low, and countries are inconsistent in provision of services across all infrastructure indicators.

Based on Afrobarometer Round 5, an earlier paper (Fry, 2015) looked at corruption in Kenya and suggested that the lack of infrastructure in that country was the source of what was described as a culture of bribery. One implication of the study was that a culture of bribery is likely to grow in the future; infrastructure will be key issue, and anti-bribery efforts should address the street level interaction between low level bureaucrats (public service providers/gatekeepers) and ordinary citizens. Police were described as part of a much larger culture of the corruption problem in Kenya. Another implication of the study was the need to look at petty, systematic corruption in a country with a more 
highly developed infrastructure, thus the choice of Cameroon as the source of the data for this paper.

\section{Method}

The study's data source is Afrobarometer, an independent, non-partisan research project that conducts surveys in more than 30 African countries, and they are repeated on a regular cycle. The data used here is based on Round 5 which the Project conducted in Cameroon in 2013. Like the previous surveys, Round 5 consisted of face to-face interviews with respondents 18 years of age and older. The sample consists of 1,200 respondents based on interviews conducted in multiple languages. The sampling frame included all of Cameroon's' provinces and the final sample provides estimates of the national population of all adults in Cameroon that is accurate to within a margin of error of plus or minus 2 percentage points at a confidence level of 95 percent. The sampling procedures that are used in all Afrobarometer surveys are explained in detail in Bratton, Mattes and Gyimah-Boadi (2005). It should be noted that this study used data generated at the individual respondent level, which is unique. Studies concerned with corruption usually rely heavily on Transparency International and its Corruption Perceptions Index (CPI) as a major data source (Retrieved from http://www.transparency.org).

\subsection{Measures and Statistics}

The dependent variable: the study's dependent variable is payment of bribes to receive public services. Survey respondents were asked a series of questions about payment of bribes for basic social services. The questions were asked in the form "in the past year, how often, if ever, have you had to pay a bribe, give a gift or do a favor to government officials?" Fixed responses for this and the other questions in the series were as follows: never, once or twice, a few times, often, no experience with this the last year and don't know. Responses were coded as follows: never and no experience with this in the last year was coded 0 (no), and once or twice, a few times and often became 1 (yes). This dichotomous variable provides the basis for the logical regression analysis presented below.

\subsection{The Independent Variables}

The study's independent variables include the other types of services on the list where possible bribes could have been paid. These included to obtain a document, receive water or sanitation services (sewer), receive treatment in a hospital or health clinic, or to receive admission or extra services in schools for a child. All of these measures were coded in the same manner as the study's dependent variable, either a yes (1) or a no (0). The interviewer and supervisor attempted to verify the availability of those public services in the respondent's local area. Respondents were also asked to rate whether obtaining certain public services was easy or difficult. They were also asked about their perceptions of the police, did the respondent's trust them? Do they think the police are corrupt? Other questions related to the police were recorded by the interviewer and verified by the supervisor, namely whether the police were visible in the area and whether a police station was located in the area. Respondents were asked whether they had been a crime victim within the last year, either a property crime victim (was something stolen from their 
house?) or were you or someone in your family a violent crime victim (Were you or someone in your family physically attacked in your home?). These Cameroonian respondents were not asked to report their income in the Afrobarometer survey. As Bratton (2008) indicated this is because many citizens in poor countries operate in informal markets where cash transactions, including income, are unrecorded and difficult to measure. Instead, this research used what is called an Asset-based Wealth Index, a summed index created from three questions that ask about household assets. The survey asks respondents: "which of these things do you personally own: A radio? A television? A motor vehicle, car or motorcycle?" Responses to these questions are binary $(0=$ don't own, $1=$ own $)$.

The measures also included a poverty index used in the Afrobarometer studies, adopted from Mattes et al. (2003). The question which generated poverty related responses were over the past year, how often, if ever, have you or anyone in your family gone without the following: enough food to eat, enough clean water for home use, without medical care, enough fuel to cook your food and a cash income. The reliability coefficient for this study was .76 (Chonback's alpha).

Some of the study's control variables were measured by a single item, like age, gender, religion, employment status, residence (rural or urban), and education, which was collapsed into 5 categories, which ranged from a none category to college/university graduation and graduate school.

\section{Results}

The basic demographic characteristics of the sample are displayed in Table 1.

Table 1. Demographic Characteristics of the Cameroon Sample $(N=1,200)$

\begin{tabular}{ll}
\hline Variable & $\mathbf{N}(\%)$ \\
\hline Age & $394(33)$ \\
18 through 25 & $461(39)$ \\
26 thru 39 & $325(28)$ \\
40 and over & \\
Gender & $594(50)$ \\
Male & $606(51)$ \\
Female & \\
Religion & $935(81)$ \\
Christian & $221(19)$ \\
Muslim & \\
Education & $122(10)$ \\
No formal/informal schooling & $214(18)$ \\
Some/Primary school completed & $572(48)$ \\
Some/completed high school &
\end{tabular}


Post-secondary/qualifications

Completed University

Grad school

\section{Employment}

Unemployed

Employed part time

Employed full time

\section{Residence}

Urban

Rural

$576(48)$

\section{Asset-based Wealth}

None of these

Radio

TV

Radio, TV and motor vehicle (car or motorcycle)
$266(22)$

Table 1 showed that this Cameroon sample was relatively young, with roughly 28 percent over 40 years of age, 39 percent in the 26 and 39 years of age group, and 33 percent in the 18 through 25 years old group. Afrobarometer samples are drawn to equally reflect the sexes, and Table 1 shows that was achieved in this Cameroonian sample. The sample was primarily Christian, 81 percent, urban, 52 percent and 70 percent of the sample was unemployed; 13 percent reported having full time employment. There was a range of responses to the educational attainment question, from none or informal education about .10 percent, to college or graduate school completion, about 11 percent. Some high school or completion of high school accounted for 48 percent of the sample. About the same percentage of respondents reported owning none of the possessions listed in the question about ownership, 20 percent, compared to 22 percent who reported owning a radio, TV and a motor vehicle (including motorcycles). About two thirds, 67 percent of the respondents reported owning a radio and a TV. Note that race was not included in Table 1. That is because there was no variation by race in this sample; 98.9 percent of the respondents were listed as Black Africans.

The next step was to examine whether certain infrastructure services were available in the local area. Those indicators are displayed in Table 2. 
Table 2. Infrastructure/Public Services Available, Visible and Respondent Crime Victimization (N $=1200$ )

Infrastructure Available

Electric grid

Yes

$1064(89)$

No

$136(11)$

Piped water

Yes

No

$168(14)$

Sewer system

Yes

808 (67)

No

$392(33)$

Police visible in area

Yes

704 (59)

No

$496(41)$

Police station in the area

Yes

No

$464(39)$

Police Corrupt

Yes

$1039(98)$

No

$21(2)$

Respondent violent crime victim

Yes

No

$981(82)$

Respondent property crime victim

Yes

No

Respondent crime victim

No

Property or violent crime

Property and violent crime

$148(12)$

Table 2 shows that 89 percent of respondents lived where the electricity grid was available, 86 percent lived where piped water was available and 67 percent resided in an area which was connected to a sewer system. The police were visible in 59 percent and there was a police station in 61 percent of the respondent's areas. Overwhelmingly, respondents thought the police were corrupt. In terms of 
victimization, 18 percent of the respondents reported a violent crime, 40 percent reported they were property crime victims. Collectively, 34 percent of the sample reported being either a violent or property crime victim, and 12 percent reported being victims of both types of crime, property and violent crime. This meant that 54 percent of the sample did not report crime victimization.

The next series of questions were those that asked respondent perceptions about either the difficulty or ease in accessing or receiving public and police services. The responses to these questions appear in Table 3.

Table 3. Respondent Perceptions of Ease or Difficulty in Accessing/Receiving Public and Police Services

\begin{tabular}{ll}
\hline Variable & $\mathbf{N}(\boldsymbol{\%})$ \\
\hline Documents, licenses, passports & $475(42)$ \\
Difficult & $670(59)$ \\
Easy & \\
Household services, water, electricity & $91379)$ \\
Difficult & $161(14)$ \\
Easy & $85(7)$ \\
Did not try & \\
Place child public school & $323(29)$ \\
Difficult & $680(61)$ \\
Easy & $109(10)$ \\
Did not try & \\
Medical treatment at a public clinic or hospital & $749(64)$ \\
Difficult & $402(34)$ \\
Easy & $18(2)$ \\
Did not try & \\
Receiving help from the police & $1049(91)$ \\
Difficult & $25(2)$ \\
Easy & $80(7)$ \\
Did not try & \\
\hline
\end{tabular}

Table 3 shows that, overall these Cameroonian respondents provided mixed responses to whether receiving public services was easy or difficult. There was a range of responses, In terms of the police, 91 percent thought it was difficult to get police services and 79 percent felt acquiring household services was difficult, like water and electricity. By way of contrast, only 29 percent felt it was difficult to place children in public school. Receipt of medical services was seen as difficult by 64 percent and 
42 percent felt obtaining documents was difficult.

The next step in the analysis was to determine the number of bribes respondents reported paying to various service providers; these results are displayed in Table 4.

Table 4 shows that 25 percent of this Cameroonian sample reported paying a bribe to the police within the last year. Another 25 percent reported paying a bribe to obtain a document, 14 percent reported bribes for sanitation services, 25 percent for health care, and 17 percent for school admission or extra assistance for a child at school. Table 3 shows that 45 percent of the sample reported paying a bribe with in the last year, and 30 percent reported paying two or more bribes during that time period.

The next step in the analysis was to determine the number of bribes respondents reported paying to various service providers; these results are displayed in Table 4.

Table 4. Payment of Bribes by Cameroon Respondents $(\mathrm{N}=1200)$

\begin{tabular}{ll}
\hline Variable & $\mathbf{N}(\%)$ \\
\hline Bribes & \\
Paid Bribe to police & $302(25)$ \\
Yes & $889(75)$ \\
No & \\
Paid Bribe to obtain document & $303(25)$ \\
Yes & $889(76)$ \\
No & \\
Paid a bribe to receive water/sanitation services & $167(14)$ \\
Yes & $1022(86)$ \\
No & \\
Paid bribe to receive health care/treatment & $297(25)$ \\
Yes & $1715(75)$ \\
No & \\
Paid bribe for school services/placement & $197(17)$ \\
Yes & $991(83)$ \\
No & \\
Total number or bribes reported paid & $180(15)$ \\
None & $154(13)$ \\
One & $81(6)$ \\
Two & \\
Three & \\
Four & \\
Five & \\
& \\
\hline
\end{tabular}


Table 4 shows that respondents paid numerous bribes in order to receive public services, with 25 percent of the sample reporting paying the police bribes, to obtain documents, and to receive health care. Another 17 percent of the respondents reported payment of bribes for school services, and 14 percent for sanitation services. While 55 percent of the sample did not report paying a bribe in the last year, 45 percent did report payment of a bribe, and 30 percent reported paying two or more bribes, with 9 percent reporting 4 or 5 payments.

The final task in the analysis was to conduct a logistical regression analysis. Because of the large number of variables included in Tables 1 through 4, a preliminary factor analysis was conducted on all of the variables included in those tables. Those that loaded on the same factor as the dependent variable, paid bribes, and had a factor loading of at least .15, were included in the logistical factor analysis. The results are displayed in Table 5 .

Table 5. Logistic Regression with Payment of Bribes as the Dependent Variable

\begin{tabular}{lllll}
\hline Variable & Coefficient & Standard Error & Z-score & P-value \\
\hline Property crime victim & .72 & .15 & 4.83 & .000 \\
Poverty & .05 & .02 & 3.31 & .000 \\
Difficulty with school & -.35 & .12 & -2.87 & .001 \\
Piped water & -.80 & .30 & -2.69 & .01 \\
Gender & -.37 & .15 & -2.52 & .01 \\
Difficulty with medical help & -.38 & .16 & -2.28 & .02 \\
Employment status & .21 & .10 & 2.04 & .04 \\
Urban-rural & .26 & .16 & 1.60 & .11 \\
Age & .15 & .10 & 1.56 & .12 \\
Religion & .30 & .21 & 1.48 & .14 \\
Difficulty with documents & .21 & .20 & 1.43 & .15 \\
On electric grid & .38 & .33 & 1.17 & .24 \\
Difficulty with police help & .33 & .30 & 1.12 & .26 \\
Sewer & -.22 & .21 & -1.11 & .27 \\
Police station in area & .16 & .19 & .87 & .39 \\
Difficulty piped water & .13 & .16 & .79 & .43 \\
*Police visible in area & .13 & .20 & .63 & .53 \\
Education & -.04 & .07 & .52 & .61 \\
Perception police corrupt & -.26 & .59 & -.44 & .66 \\
Trust the police & -.06 & .16 & -.36 & .72 \\
Constant &. $\mathbf{6 9}$ & $\mathbf{. 6 8}$ & .33 \\
Number of observations $=\mathbf{9 2 7}$ & & & & \\
\hline
\end{tabular}




\section{Chi square $=94.82$ \\ Probability $=.000$ \\ Pseudo R2 = .08}

Table 5 reveals that seven variables reached statistical significance in the logistical regression analysis; the analysis produced a pseudo $R 2$ of .08 . Being a property crime victim $(Z=4.83)$ and poverty $(Z=3.31)$ were the two strongest predictors of payment of bribes. In descending order, the other significant variables were difficulty with school services, whether the respondent had piped water, gender, difficulty with the receipt of medical assistance, and the respondent's employment status. There were some surprising findings in Table 5, and they will be discussed below.

\section{Discussion}

This paper did find support for the belief that a culture of corruption exists in Cameroon. The finding that 30 percent of the respondents reported paying two or more bribes in the previous year supports that conclusion. The findings are somewhat surprising, but make sense. The finding that deserves the most attention is the fact that property crime victimization was the strongest predictor of payment of bribes. There are several ways to begin to explain that finding. This result actually points to the role of police corruption in the generation of bribes. It also suggests the need for an improved measure regarding payment of bribes to the police. As presently presented the question asks about payment of bribes to the police and gives examples like passing a check point, avoiding a fine or arrest. There is the need to be more specific about the reasons for the payment. The check point portion is actually a given, in that the police in Cameroon and other African countries are known to routinely ask motorists for bribes to pass checkpoints and/or road blocks. That is not the same as avoiding a fine or arrest, especially an arrest. So a question about avoiding an arrest is warranted and would help clarify why the bribe was paid to the police. If respondents seem willing to report payment of bribes, why not ask the reason the bribe was paid?

The suggestion that payment of bribes to police is directly related to police corruption was supported by the data presented in this study. When payment of police bribes was cross-tabulated with being a property crime victim, it was discovered that more than half of the property crime victims had paid the police a bribe (176 of 302 or 58.3 percent). Although not as strong, violent crime victims also paid a higher percentage of bribes to the police than would be expected (70 of 216 victims or 32.4 percent). There are two different possible explanations for these findings. The first applies to property crime victimization. Respondents may believe that their failure to bribe the police will mean the police will not look for their belongings, and likely not return them if not previously bribed. The second explanation deals with violent crimes. They believe that when citizens are involved in a dispute, especially a dispute that becomes physical, the citizen that is willing to pay a bribe, the largest one, will 
become the victim and the non-payee will become the perpetrator of the violent crime.

Several of the significant factors that predict payment of bribes are clearly supported by the literature. This is the case with both gender and poverty. Simply, men are more likely to pay bribes than are women, and the poor are likely to bear the greatest burden of payment of bribes; the poor pay more. This also accounts for the fact that employment status was a significant predictor of payment of bribes. It suggests the poor pay more, but they are in fact the working poor. The other three significant predictors of payment of bribes are related to infrastructure, difficulty with school and medical services, and availability of piped water piped water.

Before the findings are addressed in more detail, it should be noted that the so-called culture of corruption is so ingrained in Africa, the question will always be "so what can we do about it?". There are several answers to that question. On the one hand, the answer is to fully develop infrastructures in African countries, and this is the goal for all African countries. Whether it will even happen by the end of this century is an open Question. The second suggestion, one that has received some attention in the literature, is to raise the wages of lower level government workers. The research on this issue is mixed. Le, de Haan and Dietzenbacher (2013) found the relationship between government wages and corruption is strong at relatively low-income levels. Van Rijckeghem and Weder (2011) used data from low-income countries to conclude that a rather large increase in wages is required to eradicate corruption solely by raising wages. Again confronting that issue the question will always be to ask where that funding would come from.

Returning to the implication of the findings, re-victimization was clearly an issue in this study. Note at the bottom of Table 2 that 148 respondents were victims of both kinds of crime, which means 12 percent of these Cameroonians were victims of both property and violent crime. This suggests the need to adopt an approach to crime prevention known as Crime Prevention Through Environmental Design (CPTED) (Cozens, 2007; Rapoport, 1982). Target hardening is central to the CPTED and refers to issues like improving locks, installing proper night lighting and clearing bushes from in front of their windows that might impede visibility of their property and neighborhoods.

\section{Conclusion}

The findings were somewhat surprising, in that Cameroon does have a more developed infrastructure than some other African countries, like Kenya, but the culture of bribery was still affirmed in Cameroon by this study. This also indicated that the locus of systematic bribery in Cameroon is the police, and lower level public service personnel that deal with infrastructure issues. The suggestion is anti-bribery programs in Cameroon should focus on the police and other public service provider bureaucrats, especially those that deal with infrastructure, as the primary agents in the rampant culture of bribery that plagues Cameroon. 


\section{Acknowledgement}

The author is grateful for the Afrobarometer Data which provided the basis for this study [Cameroon], [Round 5], [2013]. Retrieved from http://www.afrobarometer.org

\section{References}

Anoruo, E., \& Braha, H. (2005). Corruption and economic growth: The African experience. Journal of Sustainable Development in Africa, 7(1), 43-55.

Asongu, S. A. (2012). On the effect of foreign aid on corruption. African Governance and Development Institute.

Bleck, J., \& Michelitch, K. (2015). On the primacy of weak public service provision in rural Africa: Malians redefine "state breakdown" amidst 2012 political crisis (Afrobarometer Working Paper).

Blundo, G., \& Olivier de Sardan, J. P. (2006). Everyday Corruption and the State. Citizens and Public Officials in Africa, London, Zed Books.

Bratton, M, Mattes, R., \& Gyimah-Boadi, E. (2005). Public Opinion, Democracy, and Market Reform in Africa. Cambridge: Cambridge University Press.

Bratton, M. (2008). Poor People and Democratic Citizenship in Africa. In K. Anirudh (Ed.), Poverty, Participation and Democracy. New York: Cambridge University Press.

Chitakunye, P., Ojochenemi, D. J., Derera, E., \& Tarkhar, A. (2015). Transnational Analysis of the Impact of Corruption on Development in Africa: A Review of Literature (pp. 129-142).

Clausen, B., Kraay, A., \& Nyiri, Z. (2011). Corruption and Confidence in Public Institutions: Evidence from a Global Survey. The World Bank. Policy Research Working Paper Series, 5, 157.

Colombatto, E. (2003). Why is corruption tolerated? The Review of Austrian Economics, 16(4), 363-379.

Cozens, P. (2008). Public health and the potential benefits of Crime Prevention Through Environmental Design. New South Wales Public Health Bulletin, 18(11-12), 232-237.

Dominguez-Torres, C., \& Foster, V. (2011). Cameroon's Infrastructure: A Continental Perspective. World Bank Policy Research.

Egger, P., \& Winner, H. (2005). Evidence on corruption as an incentive for foreign direct investment. European journal of political economy, 21(4), 932-952.

Fry, I. (2015). The factors that predict systematic police bribery in Kenya. Global Journal of Human Social Sciences, 15(4), 29-36.

Hope, K. (2014). Kenya's corruption problem: Causes and consequences. Commonwealth and Comparative Politics, 52(4), 493-512.

Houston, D. A. (2007). Can corruption ever improve and economy? Cato Journal, 27, 325-342.

Justesen, M., \& Bjørnskov, C. (2012). Exploiting the Poor: Bureaucratic Corruption and Poverty in Africa (Afrobarometer Working paper). 
Kenny, C. (2006). Measuring and reducing the impact of corruption in infrastructure. World Bank Policy Research Working Paper, 4099, 1-42.

Kingsley, K. M. (2015). Fraud and Corruption Practices in Public Sector: The Cameroon Experience. Research Journal of Finance and Accounting, 6(4), 203-209.

Le,V. H., de Haan, J., \& Dietzenbacher, E. (2013). Do higher government wages reduce corruption? Evidence based on a novel dataset (Working Paper). Center for Economic Studies \& info Institute.

Mattes, R., Bratton, M., \& Davids, Y. (2003). Poverty, Survival, and Democracy in Southern Africa (Afrobarometer Working Paper).

Méon, P. G., \& Sekkat, K. (2005). Does corruption grease or sand the wheels of growth? Public choice, 122(1-2), 69-97.

Morello, L. B. R., \& Ramachandran, V. (2015). The face of African infrastructure: Service availability and citizens'demands (Afrobarometer Working Paper).

Ndedi, P., Alain, A., \& Mua, K. K. (2015). Challenges Facing the Fight against Fraud and Corruption Practices in the Cameroonian Public Sector.

NORAD. (2015). Cameroon Country Profile: Cameroonian Police. Retrieved from http://www.business-anti-corruption.country-profiles/sub-saharan-africa/cameroon/co

Peiffer, C., \& Rose, R. (2014). Why do some Africans pay bribes while other Africans don't (Afrobarometer Working Paper)?

Rapoport A. (1982). The Meaning of the Built Environment: A Nonverbal Communications Approach. University of Arizona Press.

Richmond, S., \& Alpin, C. (2013). Governments falter in fight to curb corruption: The people give most a failing grade (Afrobarometer Policy paper).

Siverson, R. M., \& Johnson, R. A. (2014). Politics and Parasites: The Contribution of Corruption to Human Misery. International Studies Quarterly, 58(1), 199-206.

Transparency International. (2015). Retrieved from http://www.transparency.org

Wei, S. J. (2000). How taxing is corruption on international investors? Review of economics and statistics, 82(1), 1-11.

Wong, A., \& Beckman, E. (1992). An applied ethical analysis system in business. Journal of Business Ethics, 11(3), 173-178. 